\title{
Physiological effects of bulimia nervosa on the gastrointestinal tract
}

\author{
Lisa Anderson BSc, Jill-Marie Shaw BSc, Linda McCargar PhD RD
}

\begin{abstract}
L Anderson, J-M Shaw, L McCargar. Physiological effects of bulimia nervosa on the gastrointestinal tract. Can J Gastroenterol 1997;11(5):451-459. Bulimia nervosa is an eating disorder characterized by frequent bouts of binge eating accompanied by compensatory behaviour for preventing weight gain (purging). It is estimated that $3 \%$ to $5 \%$ of young women are affected by bulimia nervosa, and its prevalence is increasing. Bulimia nervosa afflicts both sexes and all races. It can lead to serious medical complications. The expression of the disease in the gastrointestinal tract may have a critical role in the diagnosis of bulimia nervosa. Physiological effects of bulimia nervosa on the gastrointestinal tract include dental caries and enamel erosion; enlargement of the parotid gland; esophagitis; changes in gastric capacity and gastric emptying; gastric necrosis; and alterations of the intestinal mucosa. Identification of any of these factors may aid in establishing an early diagnosis, which has been shown to increase the likelihood of recovery.
\end{abstract}

Key Words: Bulimia nervosa, Eating disorder, Gastrointestinal tract, Parotid gland

$\mathrm{B}$ ulimia nervosa is an eating disorder characterized by frequent bouts of binge eating accompanied by purging to prevent weight gain (1). Large quantities of high calorie foods are ingested over a short time, ranging from a few minutes to several hours (2). The eating binges are often associated with intense emotional experiences, such as disgust, rejection, depression or stress, and are followed by strong feelings of guilt (3). After consumption of very large amounts of food, individuals with bulimia nervosa compen-

\section{Effets physiologiques de la boulimie nerveuse sur le tractus digestif}

RÉSUMÉ : La boulimie nerveuse est un trouble alimentaire caractérisé par des crises fréquentes d'excès alimentaires accompagnées de comportement compensatoire pour prévenir les gains de poids (purge). On estime que la proportion de jeunes femmes affectées de boulimie nerveuse à 3 à $5 \%$ et sa prévalence est à la hausse. La boulimie nerveuse affecte les deux sexes et toutes les races. Elle peut entraîner de graves complications médicales. L'expression de la maladie au niveau du tractus digestif peut exercer un rôle déterminant pour le diagnostic de la boulimie nerveuse. Les effets physiologiques de cette dernière sur le tractus digestif sont notamment les caries dentaires et l'érosion de l'émail, l'hypertrophie de la parotide et l'œsophagite, des altérations de la capacité gastrique et de la vidange gastrique, la nécrose gastrique et des anomalies de la muqueuse intestinale. L'identification de l'un ou l'autre de ces facteurs peut contribuer au diagnostic précoce de la maladie et en faciliter ainsi la guérison.

Department of Agricultural Food and Nutritional Science, University of Alberta, Edmonton, Alberta

Correspondence and reprints: Dr Linda McCargar, 4-10 Agriculture Forestry Centre, University of Alberta, Edmonton, Alberta T6G 2 P5.

Telephone 403-492-9287, fax 403-492-4265, e-mail mccargar@afns.ualberta.ca

Received for publication April 22, 1996. Accepted May 15, 1997 
TABLE 1

\section{Diagnostic criteria for bulimia nervosa*}

Recurrent episodes of binge eating. An episode of binge eating is
characterized by both of the following:
-eating, in a discrete period of time (ie, within any $2 \mathrm{~h}$ period),
an amount of food that is definitely larger than most people
would eat during a similar period of time under similar
circumstances
-a sense of lack of control over eating during the episode
Recurrent inappropriate compensatory behaviour in order to
prevent weight gain, such as self-induced vomiting, misuse of
laxatives, diuretics, enemas or other medications, fasting or
excessive exercise
Binge eating and compensatory behaviours that both occur, on
average, at least twice a week for three months
Self-evaluation unduly influenced by body shape and weight
The disturbances do not occur exclusively during episodes of
anorexia nervosa
*Data from reference 7

TABLE 2

Clinical gastrointestinal indicators for the diagnosis of bulimia nervosa

\begin{tabular}{|c|c|c|}
\hline Site & Indicator & Effect of bulimia \\
\hline \multirow[t]{3}{*}{ Oral cavity } & Taste perception & Hypogeusia \\
\hline & Serum amylase & Hyperamylasemia \\
\hline & Parotid gland & Hypertrophy \\
\hline Dentition & Tooth surface & $\begin{array}{l}\text { Enamel erosion* } \\
\text { Dental caries } \\
\text { Dentin hypersensitivity }\end{array}$ \\
\hline Oropharynx & Swallowing & $\begin{array}{l}\text { Dysphagia/odynophagia } \\
\text { Pattern A and B } \\
\text { Swallowing abnormalities }\end{array}$ \\
\hline Esophagus & $\begin{array}{c}\text { Esophageal } \\
\text { mucosa }\end{array}$ & Esophagitis/lesions* \\
\hline Stomach & Gastric capacity & $\begin{array}{l}\text { Increased capacity/ } \\
\text { distension }\end{array}$ \\
\hline Pancreas & Size of pancreas & $\begin{array}{l}\text { Enlarged pancreas/ } \\
\text { acute pancreatitis }\end{array}$ \\
\hline Small intestine & Peristalsis & Diarrhea/steatorrhea $^{\dagger}$ \\
\hline
\end{tabular}

${ }^{*}$ Primarily a result of self-induced vomiting; ${ }^{\dagger}$ Primarily a result of laxative abuse; may result in constipation when laxatives are withdrawn

1970s (6). A summary of the revised criteria for diagnosis (7) is shown in Table 1. It is often believed that purging is required in order for a patient to be diagnosed with bulimia nervosa; however, nonpurging mechanisms are also used to compensate for overindulgence and are part of the diagnostic criteria (7). External symptoms are limited, and, consequently, bulimia nervosa is often extremely difficult to diagnose (Table 2). Bulimic behaviours are secretive, and diagnosis is usually made through self-reporting (5) or by health care professionals who are trained in identifying the external symptoms (6).

The prevalence of bulimia nervosa is increasing (6). However, it is unclear whether this is a true increase or whether more cases are being reported. Although anorexia nervosa has been studied more extensively, bulimia nervosa is more common (6). The condition affects an estimated 3\% to $5 \%$ of young women $(8-10)$. Bulimia nervosa was once believed to be solely a women's disease, but men have been reported with the disorder (6). Bulimia nervosa has a later age of onset than anorexia nervosa, commonly occurring between ages 15 and 25 years (3). The highest prevalence of bulimia nervosa is found among university-and college-aged women (5). Individuals who fail to lose weight by conventional means may resort to bulimic behaviour $(3,5)$.

Theories of the etiology of bulimia nervosa include psychosocial, biological and biopsychosocial models, and no single model is universally accepted (5). Instead, bulimia nervosa is believed to develop from an interaction of predisposing factors and causes. The association of slimness with beauty that is accepted in industrialized societies has created an environment for the manifestation of the syndrome among predisposed individuals (5). As many as $90 \%$ of women find fault with some aspect of their body and approximately $70 \%$ of all women are preoccupied with their weight (8-10). Predisposing factors for eating disorders include a history of depression, distorted body perceptions, lack of self-esteem, compulsive behaviours and preoccupation with food (1). Family pressures and certain personality traits may also play an important role (5).

Bulimia nervosa can cause serious medical complications and may become fatal. Frequently reported medical problems include dental erosion, electrolyte imbalances resulting in metabolic alkalosis, hypochloremia, parotid gland swelling and several gastrointestinal complaints (4). Complications such as esophageal strictures, pancreatic enlargement, acute gastric dilation and gastric necrosis have been linked to bulimia nervosa (4). Patients often report symptoms of abdominal pain, bloating, early satiety associated with postprandial fullness, heartburn, diarrhea and constipation (4). The discovery of these symptoms, along with finger calluses (Russell's sign) caused by self-induced vomiting, should alert the health care professional to the possibility of bulimia nervosa (6).

This paper reviews the physiological effects on the gastrointestinal tract of repeated acute intakes of large amounts of food accompanied by compensatory behaviours. The entire gastrointestinal system from the mouth, and associated parotid glands, to the large bowel are discussed. Changes in both structure and function of many areas of the gastrointestinal tract are addressed. The identification of physiological changes are important factors in the diagnosis of a disease that is frequently missed.

\section{ORAL CAVITY}

Taste perception: Gustatory impairment is associated with the abnormal eating behaviour characteristic of bulimia nervosa (11). Jirik-Babb and Katz (11) tested the perception of taste quality and intensity by using four different log molar concentrations of sucrose, hydrochloric acid, sodium chloride and quinine hydrochloride. Their results showed significantly lower magnitude estimates of the three higher con- 
centrations of the hydrochloric acid solution, the two higher concentrations of the sucrose and sodium chloride solutions, and the highest concentration of the quinine hydrochloride solution in subjects with bulimia nervosa compared with controls. Impaired gustatory sensitivity is not believed to be caused by low body weight because individuals with bulimia nervosa are generally within their normal weight range. Jirik-Babb and Katz (11) suggested that malnutrition could be a confounding factor as a result of abnormal eating patterns, unusual food choices and frequent vomiting.

Poor taste sensitivity has also been associated with the development of trace metal deficiencies (11), in particular the functional availability of zinc (12). Trace metal deficiencies consequent to malnutrition develop over time; therefore individuals with a long history of bulimia nervosa have a high risk of developing impaired gustatory sensitivity.

Amylase levels: Alpha-amylase, an exocrine secretory protein (13), is synthesized and excreted by the pancreas and salivary glands (3). It is involved in the initial phase of digestion and is responsible for the splitting of 1,4-glycosidic bonds of complex carbohydrate $(3,14)$. Increased amylase secretion and salivary gland enlargement are characteristic of bulimia nervosa. The potential physiological mechanisms are autonomic, endocrine or mechanical in nature (14). Elevated serum amylase levels have been reported in $25 \%$ to $60 \%$ of individuals with bulimia nervosa $(14,15)$. The causative factor is unknown, and it is unclear whether bingeing, vomiting or both are necessary for the rise in serum amylase (15).

It was initially reported that both the pancreatic and salivary isoenzymes contribute to the elevated total serum amylase (16). However, it is now believed to be caused only by elevated salivary amylase secreted by the parotid, submandibular and sublingual glands $(14,17)$. Consumption of large amounts of carbohydrate-containing food may be a contributing factor $(3,16)$. Levitt et al $(18)$ speculated that elevated levels of serum amylase result from reduced clearance of the enzyme rather than increased production.

The frequency of bingeing and vomiting has been significantly correlated to higher levels of salivary amylase, a clinical indicator of enlargement of the parotid gland $(4,14$, 18-20). However, other researchers did not find a significant difference in the levels of salivary amylase in patients with bulimia nervosa versus controls $(3,16)$.

The functions of the pancreas and the parotid gland are closely related, and injury to one may cause changes to occur in the other $(4,16,21)$. In addition, humoral transmission may be involved in the interaction between the pancreas and parotid gland $(16,22)$. Pancreatic involvement should be determined first by measuring serum pancreatic isoamylase or lipase activity. Normal serum lipase activity confirms the salivary origin of hyperamylasemia and further diagnostic tests of the pancreas are not required. Kaplan (4) suggests taking a history with questions relating to weight change, eating behaviour, body image, methods of weight control and purging, as well as a psychological status examination. This information could prevent unnecessary procedures, drug prescriptions, hospitalizations and iatrogenic illnesses. Increased serum amylase levels should alert physicians to a possible diagnosis of bulimia nervosa, particularly in young women, and it may be useful in monitoring the degree of patient compliance to therapeutic programs $(16,20)$. A serum amylase level of $75 \mathrm{U} / \mathrm{L}$ or greater (normal range 25 to $115 \mathrm{U} / \mathrm{L}$ ) provides a clue related to binge-purge activity, especially if parotid enlargement and electrolyte abnormalities are apparent (15). However, others have questioned the variability in this laboratory technique $(14,18,20)$.

Parotid gland: Binge-purge behaviour may cause bilateral or unilateral enlargement of the parotid gland and occasionally of the submandibular salivary glands. Some studies suggest that parotid enlargement is intermittent and painless $(3,4$, 19,21); however, others have proposed that parotid swelling is irreversible (23) and painful (23-26). Biopsies of the enlarged parotid gland have shown an increase in acinar size due to an increased number of secretory granules, fatty infiltration and fibrosis without inflammation $(3,27)$. Other pathological studies have failed to demonstrate any significant differences in the glands, and the biopsies have been found to be benign (21) and consistent with normal parotid tissue (23). Possible explanations for enlarged parotid glands include nutritional deficiencies (25,27-29), excessive starch consumption (30), refeeding after starvation (31) and neural reflex and functional hypertrophy associated with repeated episodes of binge eating (28). Other possibilities include diabetes (32), irritation of the opening and the lining of the salivary gland ducts by gastric juices and indirect humoral effect on the glands caused by abrupt stimulation of the pancreas due to vacillations between fasting and binging (3).

Kaplan and associates (26) reported a 41-year-old Caucasian female who had a two-year history of bulimia nervosa. She was admitted to hospital with chronic inflammation in the buccal space. The area, traumatized by persistent vomiting, was inflamed around Stenson's duct. Inflammation caused impaired parotid gland drainage, increased facial swelling and tenderness. Rehydration and intravenous antibiotic therapy did not reduce the inflammation. Therefore, surgical excision was performed to exclude malignancy and improve drainage from the parotid gland. This is only one of the few cases of parotid swelling associated with pain (26). In another case of chronic bulimia, both parotid glands were surgically removed (23). Burke (23) concluded that parotid swelling may be reversed in its early stage if eating patterns return to normal. However, over time, glandular changes reach a point where they become permanent, even if a normal diet is resumed.

Parotid enlargement is a useful indicator in diagnosing and monitoring bulimia nervosa and it may eliminate unnecessary tests $(14,21)$. Physicians should question patients about their eating behaviour if parotid swelling is unexplainable $(21,26)$. Parotid hypertrophy may also occur in response to trophic stimuli released by the pancreas responding to stimuli or injury (33); therefore pancreatic pathology should be considered. Response prevention, cognitive, behavioural and group intervention, and antidepressant pharmacother- 
apy are current treatments used if swelling has not reached the irreversible stage $(14,23)$. Surgery is recommended only if parotid swelling is irreversible and is associated with chronic discomfort (23).

Oral pathology: Because bulimia nervosa is a very secretive disease and it lacks specific symptoms and physical signs, oral pathology plays an important role in its diagnosis. It is recognized that these pathologies can provide the vital link between the patient and medical intervention (34). Changes to dentition and the oral cavity, resulting from prolonged starvation and chronic vomiting, are also often irreversible (35).

The effect of bulimia nervosa on the oral soft and hard tissues depends primarily on the cariogenicity of the diet and the duration and frequency of bingeing and purging (3). The regurgitated, highly acidic gastric contents erode the enamel of the teeth (36), exposing the underlying dentin, producing acute contact and thermal hypersensitivity (3). The most frequently reported oral pathology in bulimia nervosa is the erosion of tooth enamel (78\%) (19,34,37-39). Typically, the lingual surfaces of the maxillary anterior teeth are eroded $(34,37,40)$. However, other areas of erosion may include lingual and occlusal surfaces of the maxillary posterior teeth and the lingual surfaces of the mandibular anterior teeth (34).

Additional oral pathologies that may be detected in patients with bulimia nervosa are dental caries $(78 \%)(34,39)$, dentin hypersensitivity $(68 \%)(34,37)$ or parotid dysfunction with concurrent xerostomia $(50 \%)(34,41)$. Gingival inflammation and periodontal disease occur less frequently and are not believed to be associated with bulimia nervosa $(19,34,42)$.

Dehydration of the periodontal tissues and mucous membranes results from loss of fluids and the protective properties of saliva (3). Salivary functions are reduced as a result of the wasting and dehydration effect caused by starvation (19). The quantity and composition of saliva is affected, causing an electrolyte imbalance (19). This further lowers the buffering and remineralizing capacity of the saliva, making the teeth more susceptible to acid. Vomiting also causes a sustained decrease in $\mathrm{pH}$ and contributes to increased dental erosions and caries $(19,43,44)$. Low $\mathrm{pH}$ may also encourage growth of aciduric caries-causing bacteria which has been associated with an increased incidence of tooth decay $(43,45)$. There are insufficient data to show a direct effect of an altered dietary intake on the level of bacteria (46); however, Bowen and Birkhead (47) showed a relationship between dietary carbohydrate intake and dental decay.

Bulimia nervosa should be suspected as a predisposing factor if a patient has increased caries (four lesions or more), enamel erosion and presence of other associated oral pathologies, with other diseases or conditions ruled out $(19,34)$. Bulimia nervosa must be seriously considered if parotid gland enlargement and severe enamel and dentin erosions are prevalent (19). The high frequency of dentin hypersensitivity is an indication that dental treatment is essential for patients with bulimia nervosa.

The correlation between bulimia nervosa and oral pa- thologies is not fully understood due to inconsistencies in incidence rates among patients with bulimia nervosa (34). Dental erosion may be correlated with the number of years of induced vomiting $(34,48)$; however, vomiting frequency, time period between binge eating and vomiting, and postvomiting hygiene practices must also be considered (34). Erosion generally occurs after six months of vomiting behaviour, and severity of the erosion increases with time (34), although it is highly variable among patients (19). In summary, it is believed that dental problems are related to three factors: the effects of frequent and prolonged vomiting, disturbed eating behaviour, and intraoral effects related to the wasting and dehydration status of the patient during starvation (19). Oral hygiene, cariogenicity of the diet, malnutrition, genetic predisposition, fluoride exposure during the tooth-forming years and ingestion of medication that alters saliva flow are all factors that have to be considered in this complex process $(3,49)$.

To protect teeth from the effects of chronic vomiting, preventive oral hygiene is highly recommended (34). Some authors suggest immediately brushing one's teeth after vomiting (42); in contrast, Knewitz and Drisko (50) have reported that brushing one's teeth may accelerate erosion by burnishing acid into the enamel. Neutralization of the oral cavity by rinsing with a neutral solution has been proposed by Gross and co-workers (51). Tap water rinsing immediately after vomiting may dilute the saliva too much, thereby affecting its buffering capacity and enhancing enamel erosion (34). Patients should be educated on the oral pathological changes that may result from bulimia nervosa and appropriate hygienic measures.

\section{SWALLOWING}

Dysphagia: Dysphagia and/or odynophagia may develop in patients with bulimia nervosa, especially if esophageal strictures are present (52). Birmingham et al (52) reported the first mechanical dysphagia case in a 40-year-old Caucasian female. Large bolus-sized foods became lodged under the patient's xiphisternum. Bulimia nervosa was believed to be the causative factor. The authors suggest that mechanical dysphagia may be overlooked as an underlying disorder of bulimia nervosa (52).

Salivary capacity: Saliva provides lubrication properties and is essential for food mixing, bolus formation and the initial phase of swallowing $(53,54)$. Roberts et al $(3)$ did not find any significant differences between patients with bulimia nervosa and controls in the salivary flow rates and fluid secretory capacity, for either the stimulated or unstimulated parotid and submandibular glands. Oral dryness, indicative of patients with bulimia nervosa, may be related to surface mucosal alterations and a change in ability to perceive moisture adequately (3).

Gag reflexes: Pharyngeal and velar gag reflexes may be impaired in patients with bulimia nervosa. Roberts et al (3) reported that the pharyngeal gag reflex was absent in nine of 13 bulimic patients, and a velar gag reflex was elicited in only one of the 13. Results of a cranial nerve-based oral-motor ex- 
amination revealed that the bulimic patients could not elicit a pharyngeal or velar gag reflex regardless of stimulation, with the exception of the most powerful self-inflicted tactile pharyngeal stimulation (3). This was believed to be a learned response and a form of desensitization from years of gastric purging. Frequent contact with the acidic contents of the stomach or the physical attempts to induce regurgitation are believed to have caused the highly vascularized area of the velum, typical of bulimic patients (3).

Swallowing abnormalities: Increased duration of dry swallow and abnormal oropharyngeal swallow patterns are found in subjects with bulimia nervosa (3). Oropharyngeal swallow patterns are classified into two types, A and B. Pattern A is characterized by contractile activity of the oropharynx after the bolus has been totally cleared from the pharynx and is in the esophagus. The contractions begin from the caudal end of the pharynx, the region shared by bands of muscle of the upper esophageal sphincter. These contractions move upward in a jerky, spasmodic motion, reaching the larynx, epiglottis, tongue base and the velum. The velum and the tongue do not move in synchrony. The velum elevates and contracts before lingual motion (3). Normally food passes from the oral cavity into the pharynx, the tongue moves posteriorly before and during velar elevation to close off the nasal passages, and the bolus passes over the base of the tongue and epiglottis into the lower portion of the pharynx. The contractions of pattern A may function to prepare an individual for volitional purging.

Pattern B is characterized by abnormalities in the flow and transport of the bolus from the upper pharynx through the lower pharyngeal segment, which lies above the upper esophageal sphincter. A delay in the movement of the bolus occurs as a result of deficient tongue control, and residue is left in the pharynx after swallowing. Pharyngeal wall residue and pooling of the bolus in the valleculae are observed (3). The bolus appears to drop over the base of the tongue into the pharynx and remain stationary for several centiseconds; only when the reflexive swallow is initiated does it continue to move through the pharynx. The tongue is flattened anteriorly and displaced inferiorly at its base to allow the bolus to drop into the upper pharynx and pool in the valleculae. The tongue does not move with sufficient force to generate a change in pressure within the oral cavity and therefore a delay in swallowing results. Normally the tongue causes the bolus to be propelled over its base. The combination of pattern $\mathrm{A}$ and $\mathrm{B}$ causes a disrupted and asynchronous swallowing pattern characteristic of patients with bulimia nervosa.

\section{ESOPHAGUS}

Esophageal disorders: Esophageal disorders have not been commonly associated with bulimia nervosa (52). Kiss et al (55) examined the upper gastrointestinal mucosa in $37 \mathrm{pa}$ tients with bulimia nervosa (55). These authors reported that 23 patients had normal esophageal and gastric mucosa. Eight others had mild esophagitis. The duration or severity of bulimic behaviours did not directly influence the symptoms of gastroesophageal reflux. Sliding hiatal hernias were found in two of the eight patients. Superficial mucosal erythema in the stomach or duodenum were found in six patients; esophageal erosions, ulcers or bleeding was not evident. Frequent retrosternal burning and acid regurgitation was found in three of the eight with mild esophagitis. The authors concluded that mucosal injury, esophageal perforation and gastric rupture resulting from chronic, self-induced vomiting in patients with bulimia nervosa were independent of disease history and appeared to be relatively infrequent (55).

In contrast, Birmingham et al (52) reported that the presence of highly acidic gastric contents on the esophagus can result in esophagitis, and that esophageal regurgitation and delayed stripping motion within the esophagus are found in the majority of those with bulimia nervosa. The regurgitation occurs with all consistencies of bolus material, from thin liquid to pure solid barium paste (3). Boerhaave's syndrome (rupture of the esophagus) can occur following consumption of large amounts of food and subsequent vomiting (52). Cuellar and Van Thiel (1) suggested that esophagitis, esophageal erosions, ulcers and bleeding occur frequently in patients who practise recurrent self-induced vomiting. They also concluded that the esophageal lesions result from the frequent contact of acid present in gastric secretions regurgitated into the esophagus. Cuellar et al (56) reported that five of 11 patients with bulimia nervosa had clinically important upper gastrointestinal pathology including ulcerative esophagitis, erosive gastritis, duodenal ulcer and delayed gastric emptying. They suggested that gastrointestinal disease must be specifically diagnosed and treated independently of the psychiatric treatment for patients with bulimia nervosa (56).

Lower esophageal sphincter: Altered function of the lower esophageal sphincter, apparent in patients with bulimia nervosa, also appears to be a result of induced vomiting. Initially patients may need to provoke the gag reflex using their fingers or another object (5). However, in advanced stages of bulimia, physical means may not be necessary. Reflux of gastric contents into the lower esophagus may cause relaxation of the lower esophageal sphincter (52); loss of sphincter control may be sufficient to induce vomiting (57), which could have serious consequences if a patient falls asleep with a full stomach and aspirates his or her vomit. Patients with bulimia nervosa may also learn to induce vomiting by simply contracting their abdominal muscles (5).

\section{STOMACH}

In the stomach, ingested food is mixed with hydrochloric acid and is hydrolyzed into smaller particles. The factors controlling stomach movement are myogenic, neural or chemical. It has been well established that stomach contractions increase when there is an increase in vagal activity or gastrin and motilin levels, and that contractions decrease when gastric secretions occur. When the stomach is distended, peristalsis and gastric emptying take place and digestion proceeds (58). The stomach capacity and emptying times are modified in patients with bulimia nervosa by unknown mechanisms. 
Stomach capacity: It has been hypothesized that a large stomach capacity is a contributing factor in bulimia nervosa because a larger volume of food is required to stimulate the satiety response, which leads to further bingeing and perpetuation of the syndrome. Using balloon volume to study the gastric capacity of nine patients with bulimia nervosa and nine controls, Geliebter et al (59) found that those with bulimia had a significantly larger stomach capacity. Two reasons have been suggested for this: first, binge eating may permanently expand the stomach to accommodate the excess food intake; or, second, the stomach is initially larger than average in bulimic patients, and binge eating develops from a need to ingest more food to trigger satiety mechanisms (59). If the former hypothesis is correct, the enlarged state may be temporary, and the cessation of bingeing would allow the stomach capacity to return to normal. Follow-up studies of recovered patients are necessary.

Gastric emptying: Emptying of the stomach contents into the small intestine occurs at varying rates, depending on the type and amount of food eaten (58). Previous studies have shown that patients with anorexia nervosa have delayed gastric emptying (60). Data obtained by measuring gastric emptying following the ingestion of radiolabelled liquid and solid meals did not reveal delayed emptying in bulimic patients (60). There is also no evidence to support the theory that an increase in the gastric emptying rate causes bulimia nervosa due to a lack of satiety response $(60,61)$.

More recent studies have shown alterations in the rate of gastric emptying, findings that may be due to more sensitive measurement techniques. Geliebter et al (59) used a gamma camera to measure the rate of emptying of a radiolabelled liquid meal into the small intestine. In the first 5 to 15 mins after consumption a significant decrease in emptying rate was measured, but the rate normalized after 30 mins. The authors suggested a correlation between large stomach volume and the initial decrease in emptying (59). If the stomach capacity is larger, a lower increase in intragastric pressure will occur and, therefore, a smaller contraction will occur. Kiss et al (62) also found a decrease in gastric emptying rate in bulimic patients, as well as lower amplitude of antral contractions. Overall, it is believed that gastric emptying in bulimic patients is different from that in healthy controls, and that results depend on the amount of food ingested and stomach size.

Calories absorbed during vomiting: Approximately $90 \%$ of bulimia nervosa patients engage in vomiting to purge excess calories consumed during binges (63). Despite the frequent use of this method, bulimic patients usually do not lose weight and commonly are slightly overweight (1). Compared with laxative abuse, vomiting is more effective in keeping weight under control, but does not result in weight loss (64). There have been suggestions that bulimic patients require less energy when they are not binge eating (65). One theory is that vomiting may rid the body of excess calories and lead to a decrease in metabolism. If the patient discontinues purging, he or she may become obese (66). A second theory is that vomiting is an ineffective method of calorie reduction. Me- tabolism increases during the period of consumption, but once the binge is completed, hypometabolism results due to the drastic decrease in caloric intake (66). Kaye et al (66) measured the caloric content of vomitus of 17 bulimic patients during a single binge-purge episode to determine how many calories were absorbed during that binge. The average number of calories consumed in the binges was $2131 \mathrm{kCal}$, while the average number of calories in the vomitus was $979 \mathrm{kCal}$. As the size of the binge increased, the volume of vomitus increased. Despite differences in caloric consumption, the number of calories retained remained constant at approximately $1200 \mathrm{kCal}$. Those who consumed less than $2110 \mathrm{kCal}$ retained an average of $1128 \mathrm{kCal}$, and those who consumed more than $2626 \mathrm{kCal}$ retained an average of $1209 \mathrm{kCal}$. Vomiting appears to rid the body of excess calories, especially after a large binge. It does not promote significant weight loss, but rather, appears to prevent weight gain. The reason for the $1200 \mathrm{kCal}$ maximum for retention is unknown.

Gastric abnormalities: Isolated cases of gastric dilation, spontaneous rupture of the stomach and gastric necrosis have also been reported in patients with bulimia nervosa. Gastric dilation or distension of the stomach is usually accompanied by pain and discomfort (67). In 1982, a 21-year-old college student was admitted into the emergency department with extreme gastric dilation following a large binge (67). The situation resolved when the patient was eventually able to regurgitate the stomach contents. A 30-year-old woman ingested a large volume of food and made several unsuccessful attempts to regurgitate (68). Sodium bicarbonate was ingested but did not initiate vomiting. The patient decided to seek medical aid. Upon opening the patient's abdominal cavity, three basinfuls of food were removed as a result of stomach rupture. After an aggressive treatment program the woman recovered, but suffered permanent damage to the stomach (68). In a third case, an extremely ill 17-year-old female was admitted to hospital with abdominal distension (69). The abdominal cavity was full of undigested food. The stomach was gangrenous and subsequently removed, but the patient later died of medical complications. Similarly, a 23. year-old female died from complications of abdominal distension and rupture (70). Gastric necrosis and rupture can be fatal or have severe side effects. Only a few case studies have reported an association between gastric abnormalities and bulimia nervosa. With increasing chronicity of bulimia, there is a greater risk of gastric symptoms. Stomach rupture appears to occur because of a rise in the intragastric pressure due to the very large volume of ingested food.

Pancreas: The pancreas secretes endocrine hormones, sodium bicarbonate and pancreatic enzymes in response to food intake. Two cases have been reported where patients with bulimia nervosa were admitted to hospital with pancreatic abnormalities. The attending physicians assumed that the patients had pancreatic carcinomas because the clinical features supported this diagnosis (71). A computed tomographic scan showed enlargement of the pancreas in both patients. It was later discovered that the diagnosis of bulimia nervosa had 
been missed in both cases and that acute pancreatitis likely resulted from a large binge followed by several days of fasting, or that misuse of laxatives or diuretics may have caused druginduced pancreatitis (71). These cases illustrate that bulimia is difficult to detect.

\section{BOWELS}

Small intestine: In the small intestine the products of digestion are absorbed into the blood and lymph systems. The contents of the small intestine are propelled forward and mixed by segmenting contractions and peristalsis, and the villi and microvilli facilitate nutrient absorption. If any of these processes is disrupted, malabsorption will occur. Behaviours associated with bulimia nervosa, particularly laxative abuse, affect the small intestine.

Laxative abuse: Severe stress is imposed on the small and large intestines by excessive laxative use. A review by Mitchell and Boutacoff (72) reported that $38 \%$ to $75 \%$ of bulimic patients abuse laxatives. Although there are five types of laxatives, the stimulant type is most frequently used (72). Both anthraquinones and phenolphthalein are taken by some bulimic patients in quantities that far exceed the manufacturer's recommended dosage. Stimulants are chosen because they are a fast-acting and reliable way to produce watery diarrhea (72).

There is a common belief among bulimic patients that laxatives will rid the body of a meal before it can be digested and therefore prevent weight gain. A 1983 study tested the effectiveness of stimulant-type laxatives in weight reduction by comparing the absorption of calories in control subjects with that in individuals with bulimia nervosa (73); it became evident that laxatives had a very minor effect on energy absorption. This was true even when the abuse was long term. A second study also determined that although high doses of laxatives were taken (up to 40 pills/day), they were ineffective in preventing the body from retaining calories (64). The perception of weight loss by bulimia nervosa patients can be attributed to dehydration $(72,73)$.

Even though laxatives do not aid in weight loss, their use is widespread. Initial side effects of laxative abuse include constipation and hypofunctioning of the bowel (74). With time, the body is unable to sense the need for bowel movements. Painful constipation may not resolve for several weeks after laxative withdrawal (72), and it is important for the bulimic individual to be weaned off laxatives to avoid this effect.

Damage to the surface epithelium of the colonocytes also results from chronic laxative use $(75,76)$. Comparison studies of the colonocytes of patients who abuse laxatives versus control subjects have shown chronic laxative use results in changes in shape and rarefaction of microvilli, as well as mitochondrial damage (76). Damage to epithelial cells may lead to nutrient malabsorption. A study by Bo-Linn and coworkers (73) revealed that a decrease in nutrient absorption occurs when laxatives are used, but the decrease was not linked to damaged mucosal cells.

Extensive laxative use may result in anemia due to loss of blood in the stool (72). Steatorrhea has also been reported in patients who abuse stimulant and osmotic laxatives (77), which may lead to deficiencies of the fat-soluble vitamins.

Extreme stimulant-type laxative abuse over years can lead to permanent impairment of colonic functioning known as cathartic colon (72). Symptoms include constipation, bloating and abdominal pain. Loss of haustral markings and mucosal cell atrophy are also seen in cathartic colon, changes similar to those caused by ulcerative colitis (78). Evidence of chronic inflammation in the colon due to laxative abuse has been noted (78). The effects of laxative abuse on nutrient absorption are also similar to changes seen in ulcerative colitis patients: diarrhea, steatorrhea and general malabsorption of nutrients (72). It is speculated that changes to the colon are permanent and that the patient will never regain normal bowel function (72). The formulations for stimulant laxatives have recently been modified (the more recently formulated laxatives may be less harmful), and Muller-Lissner (76) suggests that the cases of cathartic colon reported in the literature have been caused by old formulations.

Rectum: Bulimia nervosa has not been shown to cause any direct effects on the rectum. The repeated cycle of bingeing and purging may result in reduced functioning due to lack of stimulation.

Orocecal transit time: Differences in the total transit time of food from the oral cavity to the anus have been noted. Lautenbacher et al (79) measured the orocecal transit time in bulimia patients. The hydrogen breath test was used to measure lactulose breakdown. The total transit time was prolonged in bulimic patients, and it was inferred that digestion and absorption time also increased (79). Increased transit time may allow an increased number of calories to be absorbed because the gut microflora have more time to act on the food. Because only total transit time was measured, it is not known whether the increased time is due to slower gastric passage, reduced rate of intestinal flow or a combination of both.

\section{CONCLUSIONS}

The physiological effects of bulimia nervosa on the gastrointestinal tract are numerous and severe. The gastrointestinal tract undergoes tremendous insult from the effects of acute intakes of large amounts of food and the subsequent purging behaviours. Alterations in the gastrointestinal tract that occur may be interdependent on other factors, and some changes are irreversible. Individuals with bulimia nervosa can suffer from serious medical complications that may become fatal. Severity of symptoms depend on the duration and frequency of bingeing and purging, and therefore each case of bulimia nervosa is unique. External symptoms, such as parotid gland hypertrophy and dental erosions, should alert health care professionals to the possibility that an eating disorder may be present. Because the prevalence of bulimia nervosa is increasing in both sexes, early diagnosis and treatment are extremely important to ensure a favourable prognosis.

Future research to investigate the relationship between the severity and duration of bulimia nervosa and gastrointes- 
tinal disorders is necessary. Some of the syndromes may be irreversible and the risk of such occurrences needs to be established. Also, each compensatory behaviour results in a different subset of symptoms. Identification of early warning signs of excessive vomiting, laxative and diuretic abuse, prolonged fasting and excessive exercise would also be beneficial in the early detection of bulimia nervosa.

\section{REFERENCES}

1. Cuellar RE, Van Thiel DH. Gastrointestinal consequences of eating disorders: anorexia nervosa and bulimia. Am J Gastroenterol 1986;81:1113-24.

2. Mitchell JE, Pyle RL, Eckert ED. Frequency and duration of binge-eating episodes in patients with bulimia. Am J Psychiatry 1981;138:835.

3. Roberts MW, Tylenda CA, Sonies BC, Elin RJ. Dysphagia in bulimia nervosa. Dysphagia 1989;4:106-11.

4. Kaplan AS. Hyperamylasemia and bulimia: a clinical review. Int J Eat Disord 1987;6:537-43.

5. Kirkley BG. Bulimia: clinical characteristics, development, and etiology. J Am Diet Assoc 1986;86:468-75.

6. Mitchell JE, Seim HC, Colon E, Pomeroy C. Medical complications and medical management of bulimia. Ann Intern Med 1987;107:71-7.

7. Frances A, First MB, Pincus HA. Diagnostic and Statistical Manual Guidebook, 4th edn. Washington: American Psychiatric Press Inc, 1995.

8. Health and Welfare Canada. Report of the Task Force on the Treatment of Obesity. Ottawa: Health and Welfare Canada, Supply and Services, 1991:1.

9. Sheinen R. Body shame. Natl Educ Info Center Bull 1990;5:1-4.

10. Woodside DB, Garfinkel PE. An overview of eating disorders: anorexia nervosa and bulimia nervosa. NIN Review. Ottawa: National Institute of Nutrition, 1989:8.

11. Jirik-Babb P, Katz K. Impairment of taste perception in anorexia nervosa and bulimia. Int J Eat Disord 1988;7:353-60.

12. Henkin RI. Disorders of taste and smell. JAMA 1971;218:1946-8.

13. Boackle R, Suddick R. Salivary proteins and oral health. In: Menanker L, ed. The Biologic Basis of Dental Caries. New York: Harper and Row, 1980:113-31.

14. Levine JM, Walton BE, Franko DL, Jimerson DC. Serum amylase in bulimia nervosa: clinical status and pathophysiology. Int J Eat Disord 1992;12:431-9.

15. Gwirtsman HE, Watler MD, Kaye WH, et al. Hyperamylasemia and its relationship to binge-purge episodes: development of a clinically relevant laboratory test. J Clin Psychiatry 1989;50:196-204.

16. Gwirtsman HE, Yager J, Gillard BK, Lerner L. Serum amylase and its isoenzymes in normal weight bulimia. Int J Eat Disord 1986;5:355-61.

17. Humphries LL, Adams LJ, Eckfeldt JH, Levitt MD, McClain CJ. Hyperamylasemia in patients with eating disorders. Ann Intern Med 1987;106:50-2.

18. Levitt MD, Ellis CJ, Meier PB. Extra pancreatic origin of chronic unexplained hyperamylasemia. N Engl J Med 1980;302:670-1.

19. Philipp E, Willerhausen-Zonnchen B, Hamm G, Pirke KM. Oral and dental characteristics in bulimic and anorectic patients. Int J Eat Disord 1991;10:423-31.

20. Walsh BT, Wong LM, Pesce MA, Hadigan CM, Bodourian SH. Hyperamylasemia in bulimia nervosa. J Clin Psychiatry 1990;51:373-7.

21. Levin PA, Falko JM, Dison K, Gallup EM, Saunders W. Benign parotid enlargement in bulimia. Ann Intern Med 1980;93:827-9.

22. Kakizaki G, Sasahara M, Soeno T, Shoji S, Ishidate T, Senou A. Mechanism of the pancreas-parotid gland interaction. Am J Gastroenterol 1978;70:635-44.

23. Burke RC. Bulimia and parotid enlargement - case report and treatment. J Otolaryngol 1985;15:49-51.

24. Ahola SJ. Unexplained parotid enlargement: a clue to bulimia. Conn Med 1982;46:185-6.

25. Hasler JF. Parotid enlargement: a presenting sign in anorexia nervosa. Oral Surg 1982;53:575-8.

26. Kaplan AS, Woodside DB, Rutka JA. Painful buccal mass in a patient with bulimia nervosa. Int J Eat Disord 1991;10:497-500.
27. Batsakis JG, McWhirter JD. Non-neoplastic diseases of salivary glands. Am J Gastroenterol 1972;57:239.

28. DuPlessis DJ. Parotid enlargement in malnutrition. South African Med J 1956;30:700.

29. Katsilambros L. Asymptomatic enlargement of the parotid glands. JAMA 1961;178:513-4.

30. Silverman M, Perkins PL. Bilateral parotid enlargement after starch ingestion. Ann Intern Med 1966;64:842-6.

31. Watt J. Benign parotid swelling: a review. Proc R Soc Med 1970;70:483-6.

32. Davidson D, Leibel BS, Berris B. Asymptomatic parotid gland enlargement in diabetes mellitus. Ann Intern Med 1969;70:31-8.

33. Dreiling DA, Nuronna M, Nacchieko M, Peironi P, Wolfson P. The parotid and pancreas. Am J Gastroenterol 1978;70:627-34.

34. Altshuler BD, Dechow PC, Waller DA, Hardy BW. An investigation of the oral pathologies occurring in bulimia nervosa. Int J Eat Disord 1990;9:191-9.

35. Levinson NA. Oral manifestations of eating disorders: indications for a collaborative treatment approach. In: Blinder BJ, Chaitin BF, Goldstein RR, eds. The Eating Disorders. New York: PMA Publishing, 1988:405-11.

36. Kleier DJ, Aragon SB, Avervack RE. Dental management of the chronic vomiting patient. J Am Dent Assoc 1984;108:618-21.

37. Harrison JL, George LA, Cheatham JL, Zinn J. Dental effects and management of bulimia nervosa. Gen Dentistry 1985;33:65-8.

38. Hellstrom I. Oral complications in anorexia nervosa. Scand J Dent Res 1977;85:71-86.

39. Hurst PS, Lacey JH, Crisp AH. Teeth, vomiting and diet: a study of the dental characteristics of seventeen anorexia nervosa patients. Postgrad Med 1977;53:298-305.

40. House RC, Grisius R, Bliziotes MM, Licht JH. Perymolysis, unveiling the surreptitious vomiter. Oral Surg 1981;51:152-5.

41. Altshuler BC, Dechow PC, Waller DA, Hardy BW. The changes in oral tissue associated with bulimia. Dent Hyg 1988;62:49. (Abst)

42. Wolcott RB, Yager J, Gordon G. Dental sequelae to the binge-purge syndrome (bulimia): report of cases. J Am Dent Assoc 1984;109:723-5.

43. Imfeld T, Lutz F. Chronic regurgitation: continuous $\mathrm{pH}$ recordings of oral fluid. J Dent Res 1985;64:365. (Abst)

44. Larsen MJ. Dissolution of enamel. Scand J Dent Res 1973;81:518-23.

45. Meirs JC, Wirthlin MR, Shklair IL. A microbiological analysis of human early carious and non-carious fissures. J Dent Res 1982;61:460-4.

46. Liew VP, Frisken KW, Touyz SW, Beumont PJV, Williams H. Clinical and microbiological investigations of anorexia nervosa. Aust Dent J 1991;36:435-41.

47. Bowen WH, Birkhead D. Dental caries: dietary and microbiological factors. In: Granath L, McHugh WE, eds. Systemized Prevention of Oral Disease. Theory and Practice. Boca Raton: CRC Press Inc, 1986:19-41.

48. Simmons MS, Grayden SK, Mitchell JE. The need for psychiatric-dental liaison in the treatment of bulimia. Am J Psychiatry 1986;143:783-4.

49. Roberts MW, Li S. Oral findings in anorexia nervosa: a study of 47 cases. J Am Dent Assoc 1987;115:407-10.

50. Knewitz JL, Drisko CL. Anorexia nervosa and bulimia: a review. Compend Cont Educ 1987;9:244-7.

51. Gross KB, Brough KM, Randolph PM. Eating disorders: anorexia and bulimia nervosa. J Dent Child 1986;53:378-81.

52. Birmingham CL, Chang PC, Cleator IGM. Mechanical dysphagia in a patient with bulimia. Int J Eat Disord 1987;6:561-4.

53. Tylenda CA, Ship JA, Fox PC, Baum BJ. Evaluation of submandibular salivary flow rate in different age groups. J Dent Res 1988;67:1225-8.

54. Hughes CV, Baum BJ, Fox PC, et al. Oral-pharyngeal dysphagia: a common sequela of salivary gland dysfunction. Dysphagia $1987 ; 1: 173-7$

55. Kiss A, Wiesnagrotzki S, Abatzi T, Meryn S, Huabenstock A, Base W. Upper gastrointestinal endoscopy findings in patients with long-standing bulimia nervosa. Gastrointest Endosc 1989;35:516-8.

56. Cuellar RE, Kaye WH, Hsu G, Van Thiel DH. Upper gastrointestinal tract dysfunction in bulimia. Dig Dis Sci 1988;33:1549-53.

57. Brown NW. Medical consequences of eating disorders. South Med J 1985;78:403-5.

58. Rhoades R, Pflanzer R. Human Physiology. Chicago: Saunders College Publishing, 1989.

59. Geliebter A, Melton PM, McCray RS, Roberts Gallagher D, Gage D, 
Hashim SA. Gastric capacity, gastric emptying and test-meal intake in normal and bulimic women. Am J Clin Nutr 1992;56:656-61.

60. Robinson PH, Clarke M, Barrett J. Determinants of delayed gastric emptying in anorexia nervosa and bulimia nervosa. Gut 1988;29:458-64.

61. Hutson WR, Wald A. Gastric emptying in patients with bulimia nervosa and anorexia nervosa. Am J Gastroenterol 1990;85:41-6.

62. Kiss A, Bergmann H, Abatzi T, et al. Oesophageal and gastric motor activity in patients with bulimia nervosa. Gut 1990;31:259-65.

63. Mitchell JE, Hatsukami D, Pyle RL, Eckert ED, Boutacoff LI. Metabolic acidosis as a marker for laxative abuse in patients with bulimia. Int J Eat Disord 1987;6:557-60.

64. Lacey JH, Gibson E. Does laxative abuse control body weight? A comparative study of purging and vomiting bulimics. Hum Nutr:Applied Nutr 1985;39A:36-42.

65. Gwirtsman HE, Kaye WH, Obarzanek E, George DT, Jimerson DC, Ebert MH. Decreased caloric intake in normal-weight patients with bulimia: comparison with female volunteers. Am J Clin Nutr 1989;49:86-72.

66. Kaye WH, Weltzin TE, Hsu G, McConaha CW, Bolton B. Amount of calories retained after binge eating and vomiting. Am J Psychiatry 1993;150:969-71.

67. Mitchell JE, Pyle RL, Miner RA. Gastric dilatation as a complication of bulimia. Psychosomatics 1982;23:96-7.

68. Breslow M, Yates A, Shisslak C. Spontaneous rupture of the stomach: a complication of bulimia. Int J Eat Disord 1986;5:137-42.
69. Abdu RA, Garritano D, Culver O. Acute gastric necrosis in anorexia nervosa and bulimia. Arch Surg 1987;122:830-2.

70. Edwards GM. Case of bulimia nervosa presenting with acute, fatal abdominal distension. Lancet 1985;i:822-3.

71. Gilinsky NH, Humphries LL, Fried AM, McClain CJ. Computed tomographic abnormalities of the pancreas in eating disorders: a report of two cases with normal laparotomy. Int J Eat Disord 1988;7:567-72.

72. Mitchell JE, Botacoff LI. Laxative abuse complicating bulimia: medical and treatment implications. Int J Eat Disord 1986;5:325-34.

73. Bo-Linn GW, Santa Ana CA, Morawski SG, Fordtran JS. Purging and calorie absorption in bulimia patients and normal women. Ann Intern Med 1983;99:14-7.

74. Cooke WT. Laxative abuse. Clin Gastroenterol 1977;6:659-73.

75. Riemann JF, Schenk J, Ehler R, Schmidt H, Koch H. Ultrastructural changes of colonic mucosa in patients with chronic laxative misuse. Acta Hepato-Gastroenterol 1978;25:213-8.

76. Muller-Lissner SA. Adverse effects of laxative: fact and fiction. Pharmacology 1993;47:138-45.

77. Cummings JH. Progress report: laxative abuse. Gut 1974;15:758-66.

78. Kim SK, Gerle RD, Rozanski R. Cathartic colitis. Am J Roentgenol 1978;131:1079-81.

79. Lautenbacher S, Galfe G, Hoelzl R, Pirke KM. Gastrointestinal transit is delayed in patients with bulimia. Int J Eat Disord 1989;8:203-8. 


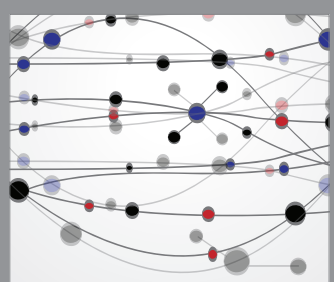

The Scientific World Journal
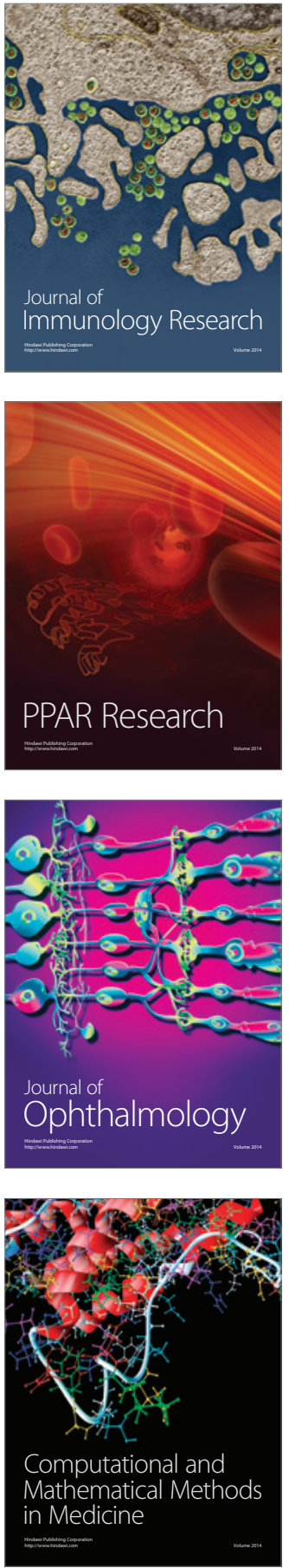

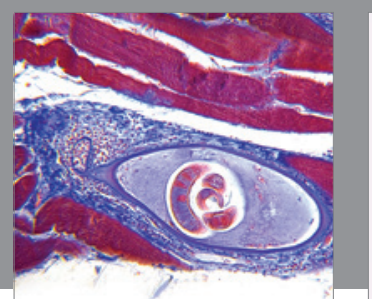

Gastroenterology Research and Practice

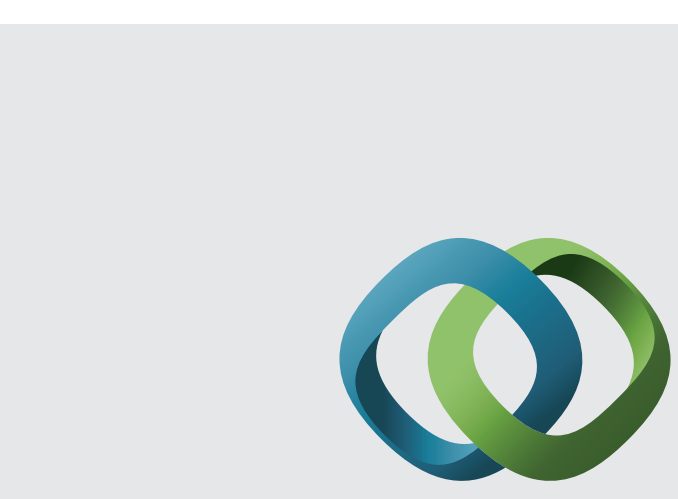

\section{Hindawi}

Submit your manuscripts at

http://www.hindawi.com
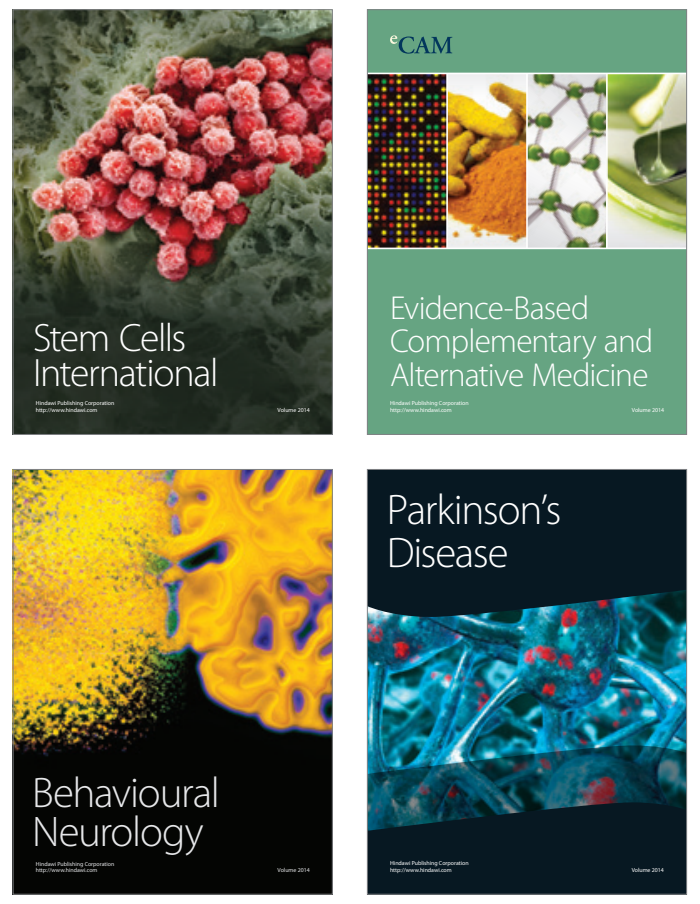
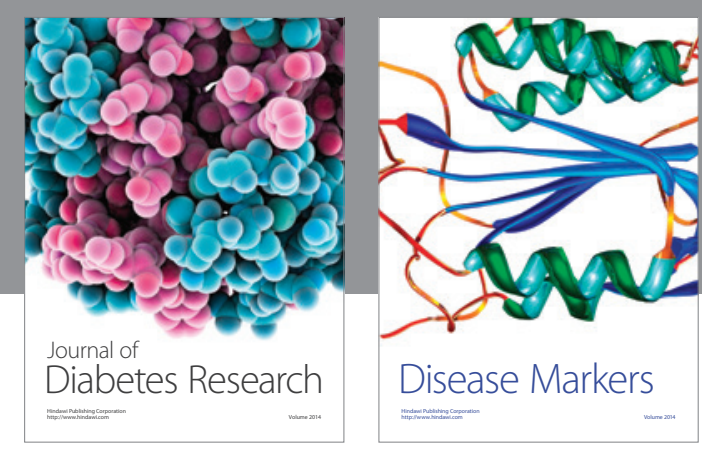

Disease Markers
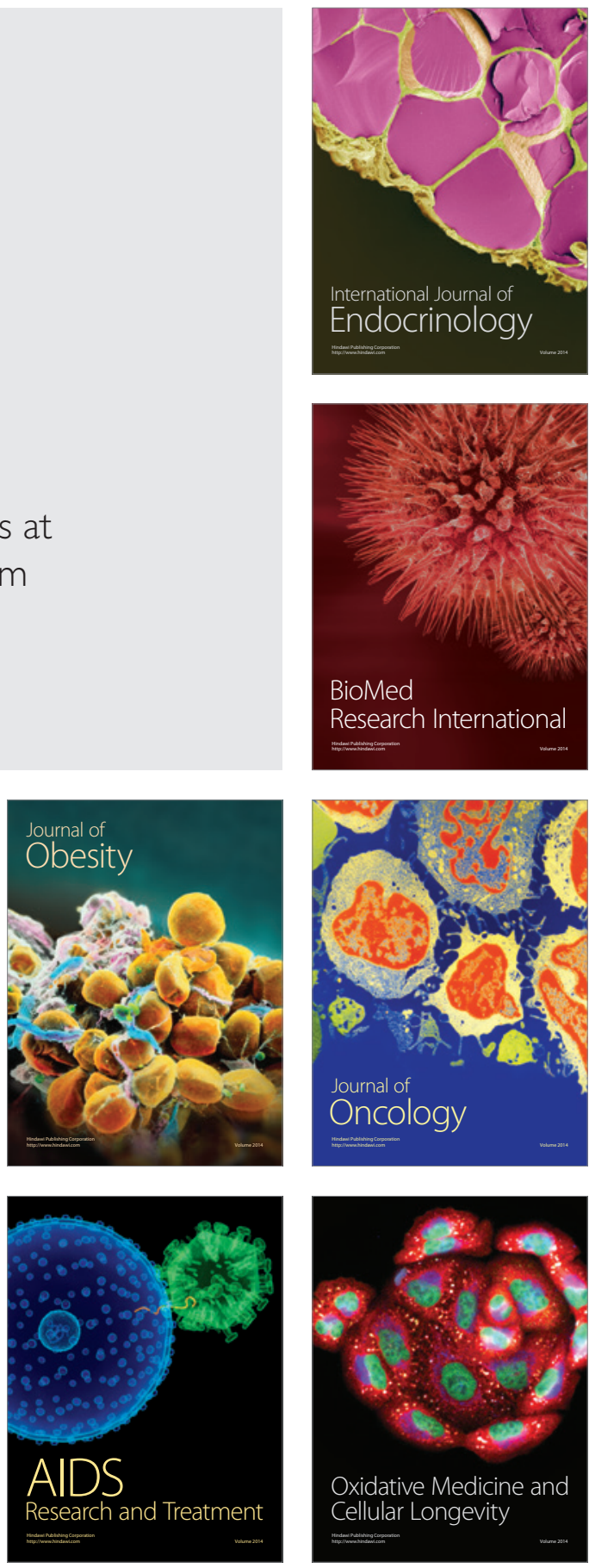